\title{
A rare colonoscopic finding in adult male with Peutz- Jeghers syndrome
}

\author{
Ahmed Youssef Altonbary* and Monir Hussein Bahgat \\ Department of Hepatology and Gastroenterology, Mansoura specialized medical hospital, Mansoura University, Egypt
}

\section{Case}

A 19-years- old male previously diagnosed as Peutz-Jeghers syndrome (PJS) was referred to our center complaining of bleeding per rectum for colonoscopy and polypectomy. Clinical examination was unremarkable except for labial hyperpigmentation characteristic of PJS (Figure 1). Colonoscopic examination showed an invaginated ileum into ascending colon (Figure 2) with a large polyp at the tip of intussusceptum (Figure 3). Snare polypectomy was not done as the duration of intussusceptions was unknown which carries high risk of perforation occurring in a background of chronic tissue ischemia. Colonoscopic air reduction was performed and invaginated ileum with the polyp was retracted to the ileoceal valve (Figure 4).

PJS is a rare autosomal dominant disorder characterized by gastrointestinal hamartomatous polyps and mucocutaneous pigmentation [1]. The polyps of PJS have been reported to cause

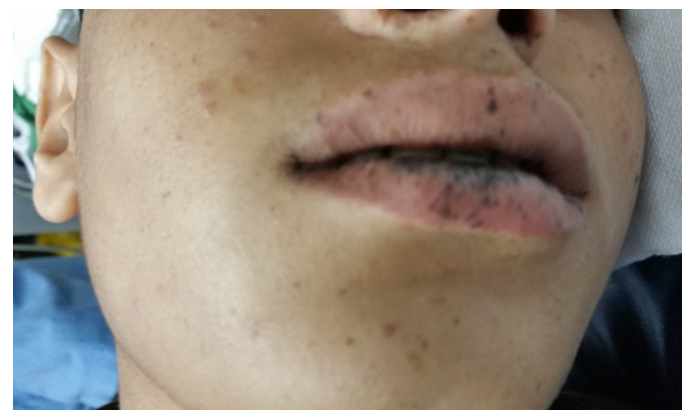

Figure 1. Labial hyperpigmentation characteristic of PJS.

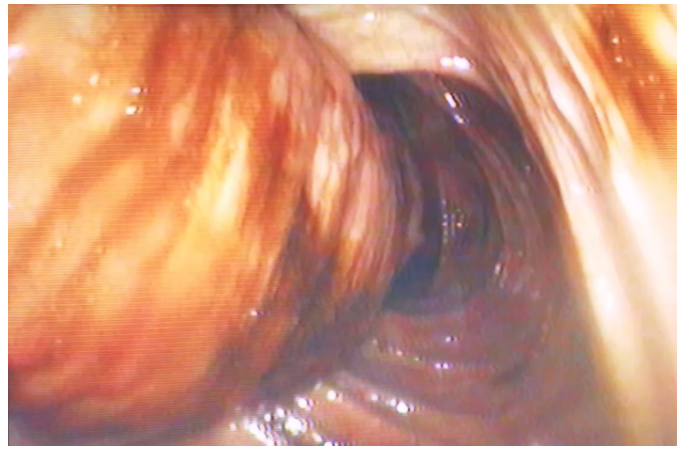

Figure 2. An invaginated ileum into ascending colon.

Copyright: (C)2016 Altonbary AY. This is an open-access article distributed under the terms of the Creative Commons Attribution License, which permits unrestricted use, distribution, and reproduction in any medium, provided the original author and source are credited. bleeding in $14 \%$ of patients. However, adult intussusception is relatively rare; only $5 \%$ of cases are in adults [2]. Most surgeons accept that adult intussusception requires surgical intervention. However, in patients with a risk of a short bowel syndrome due to multiple small intestinal polyps causing intussusception, such as PJS, a combined approach with limited intestinal resections and multiple snare polypectomies should be mandatory [3]. Our patient remained asymptomatic for 2 weeks after reduction and was referred to another center for enteroscopic polypectomy which is not available at our center.

\section{Conflicts of interest}

None declared.

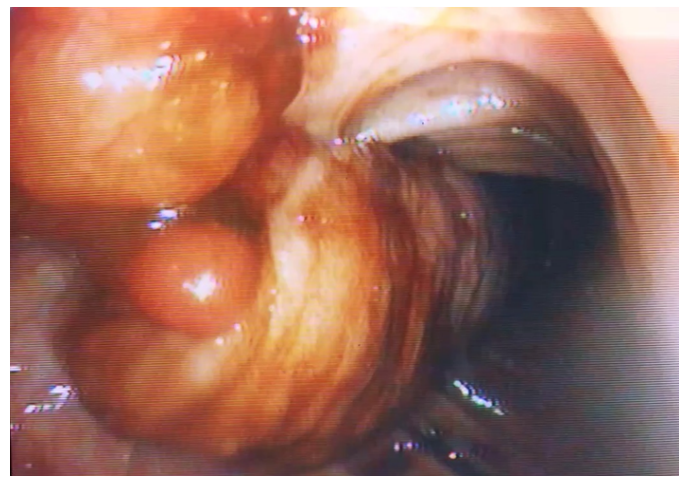

Figure 3. A large polyp at the tip of intussusceptum.

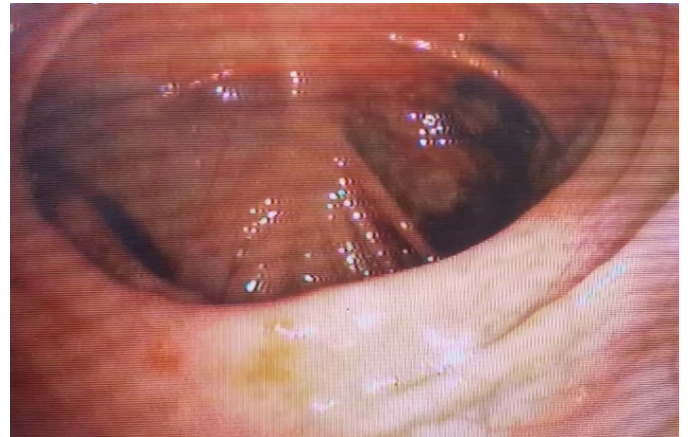

Figure 4. Invaginated ileum with the polyp retracted to the ileoceal valve.

Correspondence to: Ahmed Youssef Altonbary, Department of Hepatology and Gastroenterology, Mansoura specialized medical hospital, Mansoura University, Egypt, Tel: +201005100091, E-mail: a.tonbary@gmail.com

Received: October 31, 2016; Accepted: November 04, 2016; Published: November 07, 2016 